\title{
The analgesic efficacy of remifentanil for labour. Systematic review of the recent literature
}

\author{
Petr Stourac ${ }^{\mathrm{a}, \mathrm{b}}$, Martina Kosinova ${ }^{\mathrm{c}}$, Hana Harazimc, Martin Huser ${ }^{\mathrm{d}}$, Petr Janku ${ }^{\mathrm{d}}$, Simona Littnerovaa ${ }^{\mathrm{e}}$, Jiri Jarkovsky ${ }^{\mathrm{e}}$
}

Background and Aims. Although epidural analgesia is still regarded as the gold standard for labour analgesia due to its efficacy, in cases of contraindication, systemic remifentanil is an alternative. Since the first demonstration of the safety of remifentanil in obstetric analgesia in 1996, this has been repeatedly confirmed for both mother and newborn. The aim of this meta-analysis is to evaluate recently published studies (up to December 2014) on the analgesic efficacy of remifentanil during labour (as a Visual Analogue Scale (VAS) decrease in the first hour by 2 or more).

Methods. Search of the US National Library of Medicine, National Institutes of Health (www.pubmed.gov), SCOPUS database (www.scopus.com) and Web of Science database (www.webofknowledge.com) using the key words "labour" and "remifentanil". 44 identified articles were included in the review and 15 published randomised controlled studies were incorporated into the meta-analysis. This was based on the fixed model and described by differences in the VAS between $\mathrm{t}=0$ and $\mathrm{t}=1$ hour after remifentanil administration using the $95 \%$ confidence interval $(\mathrm{Cl})$. The analysis was computed using the Comprehensive meta-analysis version 2.2.064.

Results. The combined data from the meta-analysis showed a statistically significant decrease in VAS in the remifentanil group. From a comparison of the Cls of summary estimates with a cut-off decrease of VAS 2, for the fixed model, there was a statistically significantly greater decrease in VAS than the cut-off. In the systematic review, we describe possible modes of application, dosage and side-effects for mother, fetus/ newborn.

Conclusion. The meta-analysis presented here confirms that remifentanil for labour analgesia is effective but questions remain which can only be answered by further randomized trials.

Key words: remifentanil, labour analgesia, patient-controlled analgesia, systemic opioid analgesia, meta-analysis

Received: May 2, 2015; Accepted with revision: September 4, 2015; Available online: October 7, 2015 http://dx.doi.org/10.5507/bp.2015.043

${ }^{a}$ Department of Paediatric Anaesthesiology and Intensive Care Medicine, Faculty of Medicine, Masaryk University, Brno and University Hospital Brno, Czech Republic

${ }^{b}$ Obstetric Anaesthesia and Analgesia Section of the Czech Society of Anaesthesiology and Intensive Care Medicine, Czech Republic 'Department of Anaesthesiology and Intensive Care Medicine, Faculty of Medicine, Masaryk University, Brno and University Hospital Brno, Czech Republic

${ }^{d}$ Department of Obstetrics and Gynecology, Faculty of Medicine, Masaryk University, Brno and University Hospital Brno, Czech Republic eInstitute of Biostatistics and Analyses, Faculty of Medicine, Masaryk University, Brno, Czech Republic Corresponding author: Martina Kosinova, e-mail:mata.kosinova@gmail.com

\section{INTRODUCTION}

Most frequent contraindications to epidural analgesia, long considered the "gold" standard for labour analgesia, are refusal of parturient, congenital or acquired coagulopathy and infection ${ }^{1}$. The most commonly used opioid in the past was pethidine, despite the well-described side effects of its metabolite, norpethidine, for both mother and newborn ${ }^{2-7}$. Another currently used opioid is nalbuphine but this only reduces the pain slightly ${ }^{8-11}$.

Remifentanil is a synthetic 4-anilide-piperidine, sidechain linked by an ester bond, which is responsible for its rapid inactivation by non-specific hydrolysis of plasma and tissue esterases ${ }^{12}$. The onset time is reported on average to be $1.3 \mathrm{~min}$ and the context-sensitive half-time $3 \mathrm{~min}$, regardless of the duration of the infusion ${ }^{13}$. Remifentanil is a selective $\mu$-opioid agonist and has the same adverse effects as other opioids. The first demonstration of its use in obstetric analgesia was in 1996 and since then its safety for both mother and newborn has been repeatedly confirmed ${ }^{14-17}$.
In European countries, such as Great Britain, Belgium, France and the Scandinavian countries, the administration of remifenatnil for labour is relatively common but not nearly routine ${ }^{2,18-20}$. The reason for this may be both lack of experience of individual departments with this form of analgesia and the fact that it can be applied almost exclusively with a patient-controlled analgesia pump (PCA) (ref. ${ }^{21}$ ). Remifentanil in PCA mode is relatively well-tolerated and this increases the satisfaction of the parturient with pain management ${ }^{15,22-24}$.

The aim of this meta-analysis was to evaluate the literature on the analgesic efficacy of remifentanil during labour (measured as a Visual Analogue Scale (VAS) decrease in the first hour by 2 or more). We describe possible modes of application, dosage and side-effects for mother, fetus/ newborn.

Search of the US National Library of Medicine, National Institutes of Health (www.pubmed.gov) using the key words "labour" and "remifentanil" provided us with 159 links to publications where more than half (82) 


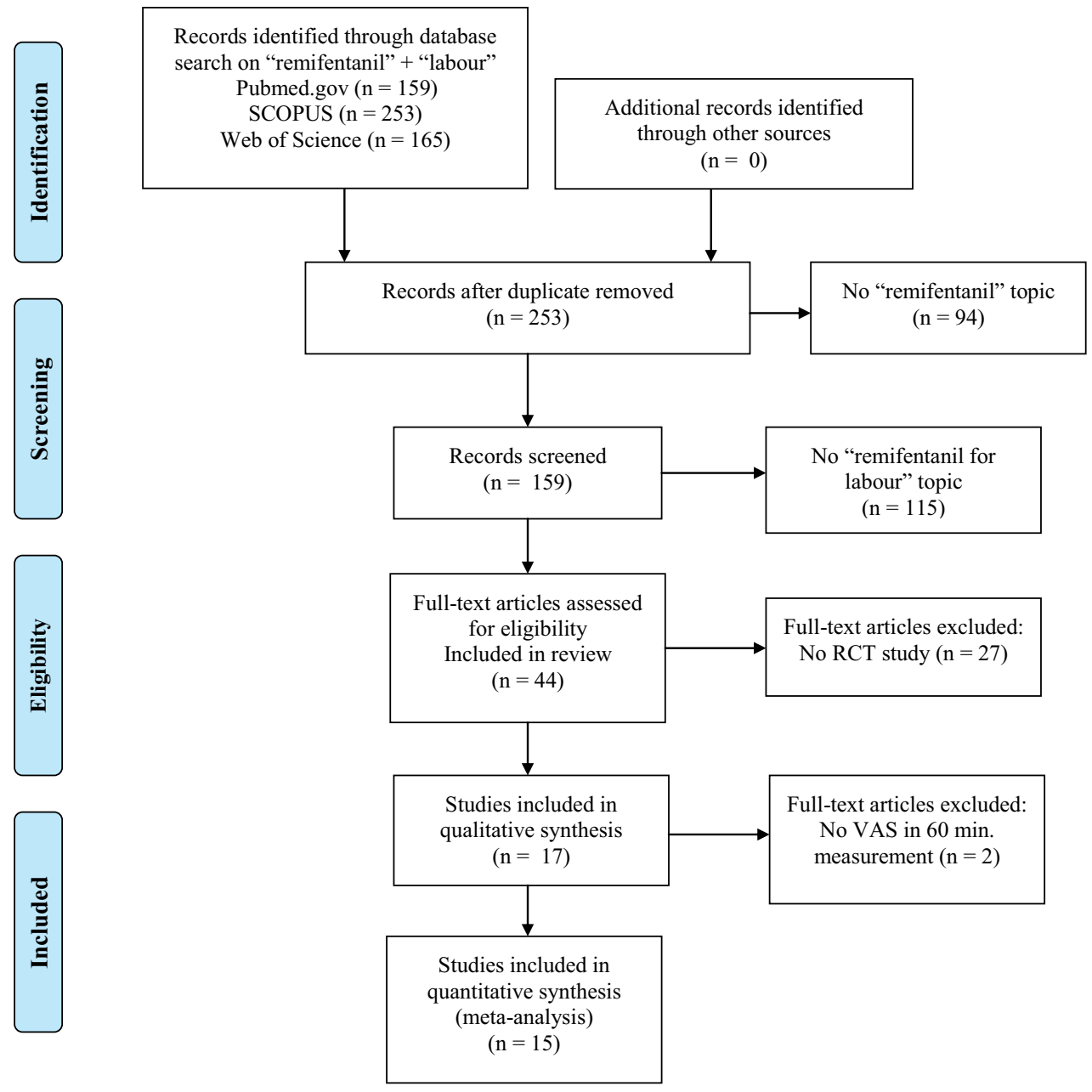

Fig. 1. PRISMA flowchart diagram.

Adopted from: Moher D, Liberati A, Tetzlaff J, Altman DG, The PRISMA Group (2009). Preferred Reporting Items for Systematic Reviews and Meta-Analyses: The PRISMA Statement. PLoS Med 6(6): e1000097. doi:10.1371/journal.pmed 1000097

were published in the last 5 years and only 30 publications were older than 10 years. This confirms that remifentanil is an extremely hot topic in labour anaesthesia.

\section{METHODS}

This article followed PRISMA Statement (www.prisma-statement.org) for meta-analysis and reviews.

\section{Searching strategy for review}

Search of the US National Library of Medicine, National Institutes of Health (www.pubmed.gov), SCOPUS database (www.scopus.com) and Web of Science database (www.webofknowledge.com) using the key words "labour" and "remifentanil". The last search was performed on December 1, 2014.

\section{Inclusion criteria for meta-analysis}

Randomized Controlled Trials (RCTs) meeting the following criteria were included: measured Visual Analogue Scale at time $0 \mathrm{~min}(\mathrm{t}=0)$ and at $60 \mathrm{~min}(\mathrm{t}=1)$ after initiation of analgesia; full-text articles available; and presence of detailed clinical data.

\section{Exclusion criteria for meta-analysis}

Not randomized controlled study. Missing full article text and missing detailed clinical data or Visual Analogue Scale at times 0 and $60 \mathrm{~min}$.

\section{Statistical analysis}

Standard descriptive statistics were applied for VAS, means and standard deviations. The meta-analysis was based on fixed model and described by the difference in the VAS between $\mathrm{t}=0$ and $\mathrm{t}=1$ in the remifentanil group and the corresponding 95\% confidence interval. The analysis was computed using the Comprehensive metaanalysis version 2.2.064.

\section{RESULTS}

\section{Flowchart}

The PRISMA flowchart is shown in Fig. 1. Five national surveys (Table 1), 7 reviews and 2 meta-analyses (Table 2), 17 randomised controlled trials (Table 3), 5 observational studies and 4 initial trials of remifentanil in labour (Table 4) and 2 case reports (Table 5) were included in this review. We also refer to two articles in the 
Czech language indexed in SCOPUS, not in pubmed.gov database. One was a Czech national survey of anaesthesiological approaches to obstetric anaesthesia and analgesia. The second was a description of analgesia for labour approaches and experiences in Great Britain ${ }^{20-21}$. In the final meta-analysis, two RCTs did not meet the inclusion criteria (measured VAS at $60 \mathrm{~min}$ ) and were excluded from the meta-analysis (Balki et al., Balcioglu et al.) (ref. ${ }^{24-25}$ ). The remaining 15 RCTs were analyzed.

\section{Characteristics of included trials}

A basic description of included RCTs (mode of administration, dosage, lock out interval, number of conversions to epidural analgesia and compared method of analgesia) is sumarized in Table 3.

\section{Primary endpoint}

The combined data from the meta-analysis shown in Table 6, revealed a statistically significant decrease in the VAS in the remifentanil group (Table $6, P<0.001$ ). Comparing CIs of summary estimates with a cut-off decrease in VAS of 2, for the fixed model, there was a sta-

\section{$\underline{\text { References }}$}

Blair et al. ${ }^{27}$

Douma et al. ${ }^{33}$

Douma et al. ${ }^{43}$

El-Kerdawy et al. ${ }^{42}$

Evron et al. ${ }^{28}$

Evron et al. ${ }^{35}$

Ismail et al. ${ }^{44}$

Ng et al. ${ }^{40}$

Stocki et al. ${ }^{17}$

Štourač et al. ${ }^{15}$

Thurlow et al. ${ }^{46}$

Tveit et al. ${ }^{34}$

Volikas et al. ${ }^{26}$

Volmanen et al. ${ }^{37}$

Volmanen et al. ${ }^{41}$

\section{Fixed model}

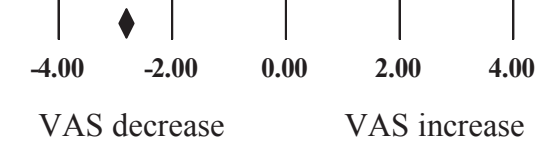

Fig. 2. Meta-analysis for VAS change in first 60 minutes of remifentanil analgesia.

VAS - Visual Analogue Scale, 95\% CI - 95\% Confidence Interval

Table 1. National surveys on labour analgesia including remifentanil.

\begin{tabular}{|c|c|c|c|}
\hline Reference & Country & $\begin{array}{l}\text { Questioned units / } \\
\text { responded/ } \\
\text { response rate [\%] }\end{array}$ & Goal or result \\
\hline Saravanakumar et al. ${ }^{2}$ & UK & $243 / 159$ / 65 & Availability of methods for pain relief other than regional block \\
\hline Schnabel et al. ${ }^{3}$ & Germany & $930 / 343 / 37$ & $\begin{array}{l}\text { Current use of intravenous opioids with a focus on remifentanil as } \\
\text { PCA in obstetrics. Remifentanil in PCA in } 68 \%\end{array}$ \\
\hline Štourač et al. ${ }^{21}$ & $\begin{array}{l}\text { Czech } \\
\text { Republic }\end{array}$ & 97 / 49 / 51 & Czech national survey on obstetric analgesia and anaesthesia \\
\hline Hanouz et al. ${ }^{18}$ & France & $240 / 103 / 43$ & $\begin{array}{l}\text { In } 52 \% \text { of French hospitals, there was a written protocol for an alter- } \\
\text { native to epidural analgesia for analgesia during labour }\end{array}$ \\
\hline Lavand'homme et al. ${ }^{19}$ & Belgium & $53 / 36 / 68$ & $\begin{array}{l}47 \% \text { of centres used PCA if epidural analgesia was contraindicated. In } \\
77 \% \text { of cases remifentanil was first choice }\end{array}$ \\
\hline
\end{tabular}

UK - United Kingdom, CR - Czech Republic, PCA - Patient controlled analgesia

Table 2. Review articles on remifentanil or other alternative labour analgesia and a meta-analysis of randomised controlled trials that compared remifentanil PCA.

\begin{tabular}{ll}
\hline Reference & Topic of review article \\
\hline Reynolds $^{7}$ & Comparison of IV opioid analgesia, Entonox, neuraxial analgesia on neonatal outcome \\
Egan $^{13}$ & Pharmacokinetics and pharmacodynamics of remifentanil \\
Leong et al. $^{38}$ & A comparison between remifentanil and meperidine for labor analgesia \\
Hill et al. $^{55}$ & The use of remifentanil in obstetric anaesthesia and analgesia \\
Hinova et al. $^{56}$ & Efficacy of remifentanil as a labor analgesic \\
Volmanen et al. $^{57}$ & Comparison of paracervical block, pudendal block, IV remifentanil and nitrous oxide \\
Kranke et al. $^{58}$ & Safety of remifentanil in labour analgesia \\
\hline
\end{tabular}

\begin{tabular}{lccl}
\hline Reference of meta-analysis & N & $\begin{array}{c}\text { n remifentanil/ } \\
\text { other }\end{array}$ & Compared methods \\
\hline Liu et al. ${ }^{14}$ & 5 RCT & $443 / 443$ & remifentanil PCA, EA \\
Schnabel et al. ${ }^{39}$ & 12 RCT & $269 / 324$ & remifentanil PCA, pethidine, nitrous oxide, fentanyl, EA \\
\hline
\end{tabular}

IV - intravenous N - number of trials, n - number of patients, RCT - randomised controlled trial, PCA - Patient controlled analgesia, EA - epidural analgesia 
Table 3. Remifentanil RCTs that evaluated the efficacy for labour analgesia.

\begin{tabular}{|c|c|c|c|c|}
\hline \multirow[b]{2}{*}{ Reference } & \multicolumn{3}{|l|}{ Remifentanil } & \multirow[b]{2}{*}{ Comparator } \\
\hline & $\begin{array}{l}\text { Bolus }[\mu \mathrm{g} / \mathrm{kg}] \\
\text { or infusion }[\mu \mathrm{g} / \mathrm{kg} / \mathrm{min}]\end{array}$ & $\begin{array}{l}\text { Lock out } \\
{[\mathrm{min}]}\end{array}$ & $\begin{array}{l}\text { Conversion to } \\
\text { EA [N] }\end{array}$ & \\
\hline Douma et al..$^{33}$ & B: 0.5 & 2 & 7 & Pethidine IV Fentanyl IV \\
\hline Evron et al. ${ }^{35}$ & B: $0.27-0.93$ & 3 & 5 & Pethidine IV \\
\hline $\mathrm{Ng}$ et al. ${ }^{40}$ & B: $0.37-0.44$ & $3.75-4.5$ & 0 & Pethidine IV \\
\hline Blair et al. ${ }^{27}$ & B: 0.5 & 2 & 2 & Pethidine IV \\
\hline Volikas et al. ${ }^{26}$ & B: 0.5 & 2 & 1 & Pethidine IV \\
\hline Štourač et al. ${ }^{15}$ & B: 0.24 & 3 & 0 & EA:Bupivacain + sufentanil \\
\hline Tveit et al. ${ }^{34}$ & B: $0.15+$ increase in steps of 0.15 until relief & 2 & 2 & EA:Ropivacain + fentanyl \\
\hline Volmanen et al. ${ }^{41}$ & B: $0.3-0.7$ & 1 & NR & EA:Levobupivacain + fentanyl \\
\hline El-Kerdawy et al. ${ }^{42}$ & $\begin{array}{l}\text { B: } 0.5 \text { loading bolus, } 0.25 \text {; I: } 0.05 \text {; } \\
(\max 3 \mathrm{mg} / 4 \mathrm{hr})\end{array}$ & 5 & NR & EA:Bupivacain + fentanyl \\
\hline Douma et al. ${ }^{43}$ & B: 0.5 & 2 & 1 & EA:Bupivacain + sufentanil \\
\hline Ismail et al. ${ }^{44}$ & B: $0.1-0.9$ & 1 & 0 & $\frac{\text { EA:Levobupivacain + fentanyl }}{\text { CSE:Levobupivacain + fentanyl }}$ \\
\hline Stocki et al. ${ }^{17}$ & B: $20-60 \mu \mathrm{g}$ & $1-2$ & 3 & EA:Bupivacain + fentanyl \\
\hline Evron et al. ${ }^{28}$ & B:20 $\mu \mathrm{g} ; \mathrm{I}: 0.025$ & 3 & NR & $\begin{array}{l}\text { EA:Ropivacain } \\
\text { EA:Ropivacain + IV remifentanil } \\
\text { EA:Ropivacain + IV acetaminophen }\end{array}$ \\
\hline Volmanen et al. ${ }^{37}$ & B: 0.4 & 1 & NR & $50 \% \mathrm{~N}_{2} \mathrm{O}$ \\
\hline Thurlow et al. ${ }^{46}$ & B: $20 \mu \mathrm{g}$ & 3 & 2 & Pethidine IM \\
\hline Balcioglu et al..$^{25^{*}}$ & $\frac{\mathrm{I}_{\mathrm{r}}: 0.1}{\mathrm{I}_{\mathrm{R}}: 0.15}$ & $\begin{array}{l}\text { NA } \\
\text { NA }\end{array}$ & NA & ( \\
\hline Balki et al. ${ }^{24}$ & Basal I: 0.025, Basal B: 0.25 & 2 & NA & $\begin{array}{l}\text { group A: I increase } 0.025-0.1 \\
\text { group B: B increase } 0.25-1\end{array}$ \\
\hline
\end{tabular}

B - bolus; I - infusion; N - number, NR - Not Reported; NA - not available, IV - intravenous, RCT - Randomized Controlled trial, EA - epidural analgesia; CSE - Combined spinal-epidural analgesia

* 2 groups with different background infusion: $\mathrm{r}(\mathrm{N}=30), \mathrm{R}(\mathrm{N}=30)$

$\mathrm{f}$ - numbers estimated from figure

tistically significantly greater decrease in VAS than the cut-off (Fig. 2).

\section{DISCUSSION AND REVIEW OF THE LITERATURE}

To the best of our knowledge, this is the first metaanalysis of RCTs on the efficacy of remifentanil during labour, regardless of study design, mode of application and dosage of remifentanil during labour.

The strength of the meta-analysis is inclusion of all RCTs published until the end of 2014 with the exception of RCTs which failed to meet the criteria for analysis.

The key information is that 12 RCTs showed a statistically significant decrease in VAS in the first hour. Two showed nonsignificant change in VAS in the first hour (Volikas et al., Blair et al.) and only one (Evron et al.) reported a statistically significant increase in VAS (ref. ${ }^{26-}$ 28). The primary outcome of Evron's study was the effect of remifentanil on body temperature during labour ${ }^{28}$. The three studies above confirmed the superiority of remifentanil in terms of analgesic efficacy compared to remifentanil with pethidine during labour.

\section{Safety and efficacy of remifentanil in labour}

As published, remifentanil relieves pain in labour during the first stage ${ }^{15,29-31}$. Typically described is initial decrease in the intensity of labour pain during the first hour following remifentanil and then a return of pain intensity to initial values, even using a different application method and dose ${ }^{14,15,29,31,32}$. Despite this course, surprisingly few subsequent applications of epidural analgesia are described for inadequate pain relief using remifentanil $(0-10 \%)$ which is hard to explain from the published data $^{28,29,33-35}$. During the second stage of labour, pain intensity remains high but the reduction in pain is perceived by the patient as adequate (Table 4$)\left(\right.$ ref. $\left.^{30,34}\right)$.

\section{Comparison of the efficacy and safety of remifentanil with other types of analgesia in labour}

There are no published RCT studies directly comparing the analgesic efficacy of remifentanil for labour with placebo.

\section{Nitrous oxide}

Nitrous oxide in the form of Entonox ${ }^{\circledR}\left(50 \% \mathrm{~N}_{2} \mathrm{O}\right.$ a $50 \% \mathrm{O}_{2}$, LINDE GAS) celebrates a return to the delivery room. Currently available is one Iranian study on the ef- 
Table 4. Observational studies of remifentanil intravenous analgesia and initial studies of remifentanil in labour.

Observational studies

\begin{tabular}{|c|c|c|c|c|c|}
\hline References & $\mathrm{n}$ & Way of $\mathrm{R}$ administration & Dose & $\begin{array}{l}\text { Lock out } \\
\text { interval }\end{array}$ & Observed parameter \\
\hline D’Onofrio et al. ${ }^{22}$ & 205 & Continuous IV & $0.02-0.15 \mu \mathrm{g} / \mathrm{kg} / \mathrm{min}$ & - & $\begin{array}{l}\text { Maternal pain, maternal and fetal } \\
\text { variables, side-effects, satisfaction }\end{array}$ \\
\hline Buehner et al. ${ }^{23}$ & 244 & PCA & $0.5-1.0 \mu \mathrm{g} / \mathrm{kg}$ & $1-2 \min$ & $\begin{array}{l}\text { Satisfaction, maternal side-effects, } \\
\text { Apgar score }\end{array}$ \\
\hline Kan et al. ${ }^{16}$ & 19 & Continuous IV & $0.1 \mu \mathrm{g} / \mathrm{kg} / \mathrm{min}$ & - & $\begin{array}{l}\text { Concentrations of remifentanil, its } \\
\text { metabolite, and blood gases in MA, } \\
\text { UA and UV blood samples }\end{array}$ \\
\hline Volikas et al. ${ }^{29}$ & 50 & PCA & $0.5 \mu \mathrm{g} / \mathrm{kg}$ & $2 \mathrm{~min}$ & $\begin{array}{l}\text { VAS, nausea, itching, fetal heart } \\
\text { rate, UA gases, } 1 \text { and } 5 \text { min Apgar } \\
\text { scores, neurological evaluation of } \\
\text { the neonate, remifentanil concentra- } \\
\text { tion in MV, UA, UV blood samples }\end{array}$ \\
\hline Marwah et al. ${ }^{32}$ & 98 & PCA & $\begin{array}{l}\text { B: } 0.25 \mu \mathrm{g} / \mathrm{kg}, \\
\text { I: } 0.025-0.05 \mu \mathrm{g} / \mathrm{kg} / \mathrm{min}\end{array}$ & $2 \min$ & $\begin{array}{l}\text { Maternal pain scores, sedation } \\
\text { scores, adverse effects, neonatal } \\
\text { outcomes }\end{array}$ \\
\hline
\end{tabular}

Initial studies

\begin{tabular}{lrll}
\hline References & $\mathrm{n}$ & Type of study & Goal \\
\hline Blair et al. $^{30}$ & 21 & Feasibility study & Remifentanil PCA (B 0.25-0.5 $\mu \mathrm{g} / \mathrm{kg})$ \\
Volmanen et al. $^{31}$ & 17 & Dose finding study & The median effective PCA: B: 0.4 $\mu \mathrm{g} / \mathrm{kg}, \mathrm{I}: 0.066 \mu \mathrm{g} / \mathrm{kg} / \mathrm{min}$ \\
${\text { Huang et al. }{ }^{45}}_{\text {Babenco et al. }^{48}}$ & 0 & Experimental analysis & Prediction of the occurrence of labor contractions \\
\hline
\end{tabular}

n - number of patients; IV - intravenous, PCA - Patient controlled analgesia, NA - Not Available, R - remifentanil, MV - maternal vena, MA maternal arteria, UA - umbilical arteria, UV - umbilical vena, VAS - Visual Analogue Scale, B = bolus, I = basal infusion

ficacy and safety of nitrous oxide during labour. It describes a surprisingly high incidence of side-effects ${ }^{36}$. The analgesic efficacy of remifentanil compared to $50 \% \mathrm{~N}_{2} \mathrm{O}$ was five times higher than that published by Volmanen et al. ${ }^{37}$ Mothers themselves preferred the administration of remifentanil. The disadvantage of remifentanil was a higher level of sedation but no serious episodes of hypoxia ( $\mathrm{SpO} 2<90 \%$ ) occurred. The authors found no differences in maternal hemodynamics or early postnatal adaptation of newborns.

\section{Pethidine}

A systematic review comparing the use of remifentanil and pethidine in the management of labour pain, clearly documents the greater efficacy of remifentanil ${ }^{38}$. In this study, remifentanil was more effective on the VAS scale 25 millimeters, than pethidine within the first hour after application. The maternal satisfaction with remifentanil was higher and necessity for subsequent application of epidural analgesia for inadequate pain relief was lower ${ }^{39}$. Due to the large heterogeneity of dosing schedules of both drugs, it is difficult to draw clear conclusions about the side-effects. There were no differences in the incidence of decreased saturation below $95 \%$ or in maternal sedation. Some studies found no difference in cardiotocograph interpretation ${ }^{33,40}$. On the other hand, one study showed a lower incidence of non-physiological cardiotocograph when remifentanil was administered ${ }^{35}$. All studies confirmed better postpartum neonatal outcome after remifentanil than pethidine (Table 3) (ref. ${ }^{26,27}$ ).

\section{Epidural analgesia}

The most interesting and most useful in practice, is comparison of remifentanil with epidural analgesia. Although epidural analgesia is provided in less than $15 \%$ of labours in some countries, it is the major analgesic method used by anaesthesiologists in obstetrics in the Czech Republic ${ }^{21}$. Currently, few probably doubt that remifentanil administered in the PCA is a less effective analgesic than epidural analgesia ${ }^{14,15}$. Despite these findings, most studies found no difference in maternal satisfaction with applied method of analgesia ${ }^{15,18,34,41-44}$. This would suggest that remifentanil provides a weaker but highly acceptable analgesia for the parturient. The explanation for this may be opioid-induced euphoria ${ }^{41}$. In contrast, remifentanil is associated with a higher risk of nausea and vomiting, decreased oxygen saturation under $95 \%$ and dose dependent level of sedation ${ }^{34,39,41}$. There was no difference in either cardiotocograph interpretation or neonatal outcome between epidural analgesia and remifentanil $1^{15,28,34,41,43,44}$. No effect on higher incidence of instrumental deliveries, Caesarean Sections or length of 
Table 5. Case reports of patients using patient controlled analgesia.

\begin{tabular}{ll}
\hline Reference & Case description \\
\hline Bonner et al. ${ }^{53}$ & Respiratory arrest in patient using remifentanil in PCA \\
Marr et al..$^{54}$ & $\begin{array}{l}\text { Cardiorespiratory arrest during induced labour while using a remifentanil PCA in patient diagnosed } \\
\text { with an intrauterine death at 31 weeks' gestation }\end{array}$ \\
\hline
\end{tabular}

PCA - Patient controlled analgesia

Table 6. Meta-analysis of study results comparing VAS between $\mathrm{t}=0$ and $\mathrm{t}=1$ hour for remifentanil.

\begin{tabular}{|c|c|c|}
\hline Study & $\begin{array}{l}\text { Difference in VAS between } \mathrm{t}=0 \text { and } \mathrm{t}=1 \\
\text { for Remifentanil }(95 \% \mathrm{CI})\end{array}$ & $P$ \\
\hline Blair et al. $^{2 \prime}$ & $0.300(-1.324 ; 1.924)$ & 0.718 \\
\hline Douma et al. ${ }^{33}$ & $-3.240(-4.024 ;-2.456)$ & $<0.001$ \\
\hline Douma et al. ${ }^{43}$ & $-3.800(-5.387 ;-2.213)$ & $<0.001$ \\
\hline El-Kerdawy et al. ${ }^{42}$ & $-4.900(-5.898 ;-3.902)$ & $<0.001$ \\
\hline Evron et al. ${ }^{28}$ & $1.900(1.399 ; 2.401)$ & $<0.001$ \\
\hline Evron et al. ${ }^{35}$ & $-5.040(-5.931 ;-4.149)$ & $<0.001$ \\
\hline Ismail et al. ${ }^{44}$ & $-3.210(-3.362 ;-3.058)$ & $<0.001$ \\
\hline $\mathrm{Ng}$ et al. ${ }^{40}$ & $-3.220(-4.491 ;-1.949)$ & $<0.001$ \\
\hline Stocki et al. ${ }^{17}$ & $-4.100(-5.072 ;-3.128)$ & $<0.001$ \\
\hline Štourač et al. ${ }^{15}$ & $-2.400(-2.850 ;-1.950)$ & $<0.001$ \\
\hline Thirlow et al. ${ }^{46}$ & $-2.300(-3.850 ;-0.750)$ & 0.006 \\
\hline Tveit et al. ${ }^{34}$ & $-4.400(-5.437 ;-3.363)$ & $<0.001$ \\
\hline Volikas et al. $^{26}$ & $-1.900(-4.487 ; 0.687)$ & 0.162 \\
\hline Volmanen et al. ${ }^{37}$ & $-1.900(-3.072 ;-0.728)$ & 0.003 \\
\hline Volmanen et al. ${ }^{41}$ & $-1.000(-1.854 ;-0.146)$ & 0.025 \\
\hline Summary - fixed model & $-2.826(-2.953 ;-2.699)$ & $<0.001$ \\
\hline
\end{tabular}

VAS - Visual Analogue Scale, 95\% CI - 95\% Confidence Interval

delivery stages 1 and 2 were established either (Table 3) $\left(\right.$ ref. $\left.^{15,17}\right)$.

\section{Dosing and mode of remifentanil administration during labour}

Remifentanil is administered intravenously using infusion pump with PCA mode preferably without any further IV fluid administered into identical intravenous cannula. Currently available are various products containing remifentanil: Ultiva (GSK, Great Britain), Remifentanil B.Braun (B.Braun, Germany), Remifentanil Kabi (Fresenius Kabi, Germany) and others. The package contains 1 or $2 \mathrm{mg}$ of active substance in the vial. Remifentanil usually needs to be diluted with saline to achieve a concentration of 20 or $50 \mu \mathrm{g} / \mathrm{mL}$ (ref. ${ }^{15,20}$ ). The setup for PCA mode in published studies is variable and optimal dosing schedules have not yet been described (Table 3) (ref. ${ }^{14}$ ).

\section{Bolus versus continuus application}

The first dose determining studies identified the effective dose as $0.25-0.5 \mu \mathrm{g} / \mathrm{kg}$ for obstetric analgesia (Table 4) (ref. ${ }^{30,31}$ ). Subsequent studies have worked with different dosages ranging from $0.1-0.9 \mu \mathrm{g} / \mathrm{kg}$ in case of conversion of the dose per body weight or fixed bolus 20-50 $\mu$ g (ref. ${ }^{15}$ ). Lock out interval (interval in which the pump does not respond to parturient requirements) varied between 1 and 3 min with the exception of two studies, where the lock out interval was $4.5 \mathrm{~min}$ and $5 \mathrm{~min}^{40,42}$. A maximum average single dose of $0.7 \mu \mathrm{g} / \mathrm{kg}$ was published by Tveit. This author also warned about exceeding this dose because of higher risk of desaturation and maternal sedation $^{34}$. On the other hand, D'Onofrio did not apply bolus doses, only continual infusion of remifentanil in a range of 0.025 to $0.15 \mu \mathrm{g} / \mathrm{kg} / \mathrm{min}$ (ref. ${ }^{22}$ ).

\section{Fixed versus variable dose of remifentanil}

Labour pain is intermittent, dynamic and specific with increasing frequency and intensity during labour progression. For this reason, proper timing, dosing and length of lock out interval are important for analgesic efficacy. The beginning of subsequent contractions is also unpredictable due to interindividual variability even with the involvement of highly advanced machine learning methods ${ }^{45}$. This fact could explain the considerable variation in dose and cumulative dose of remifentanil during labour in most published studies ${ }^{12}$. A fixed dose without the option of reacting to actual need can therefore lead to either underdosing with unsufficient pain relief or overdosing associated with side-effects ${ }^{27,46}$. Some studies refute this concern $^{33,40,43}$. The question of preferences of fixed dose or variable dose therefore remains open. 


\section{Basal infusion}

Another controversial issue in the administration of remifentanil at delivery, is application of basal infusion in the period between bolus applications. In studies where basal infusion was used, the dose varied between 0.025 and $0.15 \mu \mathrm{g} / \mathrm{kg} / \mathrm{min}$. Blair et al. reported that basal infusion does not lead to greater analgesic efficacy but only to higher incidence of respiratory depression and maternal sedation $^{30}$. On the other hand, Balki explained the low rate of need for loading epidural analgesia due to inefficacy of remifentanil with administering the variable basal infusion $(0.025-0.1 \mu \mathrm{g} / \mathrm{kg} / \mathrm{min}$ with bolus dose $0.25 \mu \mathrm{g}$ / $\mathrm{kg})\left(\right.$ ref. $\left.^{24}\right)$.

\section{Comparison of different modes of administration of remifentanil}

Few studies are available that directly compare different modes of administering remifentanil at delivery. Balcioglu et al. compared two PCA modes with different basal infusion of remifentanil. A basal infusion of $0.15 \mu \mathrm{g} /$ $\mathrm{kg} / \mathrm{min}$ was found to be the more effective analgesic dose than $0.1 \mu \mathrm{g} / \mathrm{kg} / \mathrm{min}$ without the described difference in adverse effects for both mother and newborn ${ }^{25}$. Balki et al. compared two modes of remifentanil administration, one with variable bolus dose and fixed basal infusion and in contrast, the second with variable basal infusion and fixed bolus dose $\mathrm{e}^{24}$. Analgesic efficacy, maternal satisfaction and cumulative intake of remifentanil were comparable. Sideeffects, especially drowsiness, were higher in the group with the variable bolus. Apropos the pharmacokinetics of remifentanil and the character of labour pain, initiation of remifentanil administration with the beginning of contraction may not lead to the greatest effect at the time of the most intensive labour pain ${ }^{47,48}$. For this reason, Volmanen et al. investigated remifentanil administration either at the beginning of contraction or between two contractions ${ }^{49}$. They reported no differences in analgesic efficacy or incidence of side-effects between groups. However, more detailed analysis showed that in a group of patients with long and regular contractions, a bolus dose between contractions can have greater analgesic effects.

\section{Adverse effects of remifentanil in labour}

Remifentanil, as with other opioids, can potentially cause serious adverse effects. Various depth of maternal sedation is common ${ }^{15,29,31,37,41}$. The incidence of sedation in some studies is almost $100 \%$ (ref. $^{24,31,34}$ ). Other frequent negative effects of opioids, including remifentanil are nausea and vomiting. Some publications do not describe a higher incidence in the case of remifentanil ${ }^{14,15,17,24,31,34}$. The occurrence of dizziness may disable further use of remifentanil due to risk of falling during verticalization $^{40,41}$. An incidence of maternal desaturation under $95 \%$ is published in $24-74 \%$ of cases $^{17,30,31,33,41,46}$. This is no higher than pethidine ${ }^{38}$. Interestingly, desaturation occurs in $40 \%$ of parturients inhaling Entonox ${ }^{\circledR}$ and in $46 \%$ of parturients without any analgesia ${ }^{50,51}$. Episodes of desaturation associated with remifentanil are usually short and rapidly respond to maternal stimulation or oxygen application. The most severe cases may result in apnea and several have been reported ${ }^{17,52-54}$. The one requiring artificial ventilation reported by Bonner and McClymont was related to a combination of other factors such as dehydration, exhaustion and vertical position of the parturient $^{53}$. Recently, a case report of cardiac arrest following respiratory arrest after remifentanil was published ${ }^{54}$. Long term opioids (codein, diamorphine) preceded this event in the reported case. Although the full recovery of parturient occurred after resuscitation, fatal intrauterine death took place during the complication. This incident led to recommendations for careful maternal monitoring after remifentanil, including continuous monitoring of respiratory rate and oxygen saturation and one midwife per parturient. There is also the need for rapid availability of anaesthesiologist to deal with any complications ${ }^{24,27,55-57}$. Implementation all of these conditions may not be easy to achieve in an exposed delivery room in a large perinatological center. After the initial labelling of remifentanil as "The poor man's epidural", it seems that for its safe use we must require at least the same conditions as for epidural analgesia ${ }^{58}$.

\section{Adverse effects of remifentanil on the fetus and neonate}

Although remifentanil rapidly crosses the placenta into the fetal circulation ( $88 \%$ concentration in the fetus), it is rapidly metabolized and redistributed in newborn (the concentration ratio uterine vein to uterine artery is 0.29) $\left(\right.$ ref. $^{16}$ ). The risk for neonate appears to be minimal. Further studies confirm this and to date no adverse neonatal outcome (Apgar score, uterine blood gases or need to give naloxone) has been proven ${ }^{14,15,17,22,23,30,43}$. Neither has any typical pathological cardiotocograph curve associated with remifentanil in labour been found. One caveat is the small number of cases of impaired neonatal outcome that may cause a feeling of false security around remifentanil use for newborns ${ }^{29}$. For this reason, the necessary equipment of the delivery room for eventual resuscitation of newborns must include naloxone. Based on the current published data, we cannot answer questions concerning the relationship of possible impairment in neonatal outcome and dosage to the method of application of remifentanil.

However, we recommend the following dose regimen without background infusion, low initial dose with the option of bolus adjustment or/and lock out intervals based on clinical status of the parturient and termination of boluses at the start of the second stage of labour, to minimise maternal hypoventilation and adverse postnatal effects on the newborn ${ }^{59}$.

\section{CONCLUSION}

This meta-analysis confirms the efficacy of remifentanil for labour. The systematic review describes possible modes of application, dosage and side-effects for mother, fetus/ newborn. However, questions remain which can only be answered by further randomized trials. 
Acknowledgement: Many thanks to Alena Stouracova for review of the article and Alexander Oulton for proof reading.

Author contributions: PS, MK, HH, MH, PJ, SL, JJ: designed the meta-analysis and review, literature search, statistical analysis, manuscript writing, final approval, SL, JJ: statistical analysis, graphs.

Conflict of interest statement: The authors state that there are no conflicts of interest regarding the publication of this article.

\section{REFERENCES}

1. Bonnet A, Chevalier Y, Wallon G, Huissoud C, Aubrun F. Peripartum period and hemophilia carriers. Ann Fr Anesth Reanim 2013;32(11):807-10.

2. Saravanakumar K, Garstang JS, Hasan K. Intravenous patient-controlled analgesia for labour: a survey of UK practice. Int J Obstet Anesth 2007;16(3):221-5.

3. Schnabel A, Hahn N, Muellenbach R, Frambach T, Hoenig A, Roewer $\mathrm{N}$, Kranke P. Obstetric analgesia in German clinics. remifentanil as alternative to regional analgesia. Anaesthesist 2011;60(11):995-1001.

4. Pařizek A, Bláha J, Nosková P. [Obstetric analgesia and anesthesia in the Czech Republic in 2012. 20th anniversary of postgraduate education program]. Ceska Gynekologie 2012;77(4):346-9. [In Czech].

5. Belfrage P, Boréus LO, Hartvig P, Irestedt L, Raabe N. Neonatal depression after obstetrical analgesia with pethidine. The role of the injection-delivery time interval and of the plasma concentrations of pethidine and norpethidine. Acta Obstet Gynecol Scand 1981;60(1):43-9.

6. Kuhnert BR, Philipson EH, Kuhnert PM, Syracuse CD. Disposition of meperidine and normeperidine following multiple doses during labor. II. Fetus and neonate. Am J Obstet Gynecol 1985;151(3):410-5.

7. Reynolds $F$. The effects of maternal labour analgesia on the fetus. Best Pract Res Clin Obstet Gynaecol 2010;24(3):289-302.

8. Vavřinková B, Binder T, Horák J. [Nalbuphine in obstetrical analgesia.] Ceska Gynekologie 2010;75(6):563-8. [In Czech]

9. Soontrapa S, Somboonporn W, Komwilaisak R, Sookpanya S. Effectiveness of intravenous meperidine for pain relief in the first stage of labour. J Med Assoc Thai 2002;85(11):1169-75.

10. Olofsson C, Ekblom A, Ekman-Ordeberg G, Hjelm A, Irestedt L. Lack of analgesic effect of systemically administered morphine or pethidine on labour pain. Br J Obstet Gynaecol 1996;103(10):968-72.

11. Tsui MH, Ngan Kee WD, Ng FF, Lau TK. A double blinded randomised placebo-controlled study of intramuscular pethidine for pain relief in the first stage of labour. Br J Obstet Gynaecol 2004;111(7):648-55.

12. Glass PS, Hardman D, Kamiyama Y, Quill TJ, Marton G, Donn KH, Grosse CM, Hermann D. Preliminary pharmacokinetics and pharmacodynamics of an ultra-short-acting opioid: remifentanil (Gl87084B) Anesth Analg 1993;77(5):1031-40.

13. Egan TD. Pharmacokinetics and pharmacodynamics of remifentanil: an update in the year 2000. Curr Opin Anaesthesiol 2000;13(4):44955.

14. Liu ZQ, Chen XB, Li HB, Qiu MT, Duan T. A comparison of remifentanil parturient-controlled intravenous analgesia with epidural analgesia: a meta-analysis of randomized controlled trials. Anesth Analg 2014; 118(3):598-603.

15. Stourac P, Suchomelova H, Stodulkova M, Huser M, Krikava I, Janku P, Haklova O, Hakl L, Stoudek R, Gal R, Sevcik P. Comparison of Parturient-Controlled Remifentanil with Epidural Bupivacain and Sufentanil for Labour Analgesia: Randomised Controlled Trial. Biomed Pap Med Fac Univ Palacky Olomouc Czech Repub 2014;158(2):227-32.

16. Kan RE, Hughes SC, Rosen MA, Kessin C, Preston PG, Lobo EP Intravenous remifentanil: placental transfer, maternal and neonata effects. Anesthesiology 1998;88(6):1467-74.

17. Stocki D, Matot I, Einav S, Eventov-Friedman S, Ginosar Y, Weiniger CF. A Randomized Controlled Trial of the Efficacy and Respiratory Effects of Patient-Controlled Intravenous Remifentanil Analgesia and
Patient-Controlled Epidural Analgesia in Laboring Women. Anesth Analg 2014;118(3):589-97.

18. Hanouz JL, Simonet T, Marliot C, Mayaud A, Girard A, Rakotnirina $\mathrm{N}$, Fellahi JL, Gérard JL. French national survey on remifentanil utilisation for obstetrical peridural analgesia. Ann Fr Anesth Reanim 2012;31(9):682-6. [In French]

19. Lavand'homme P, Roelants F. Patient-controlled intravenous analgesia as an alternative to epidural analgesia during labor: questioning the use of the shortacting opioid remifentanil. Survey in the French part of Belgium (Wallonia and Brussels). Acta Anaesthesiol Belg 2009;60(2):75-82.

20. Matloch Z, Matlochová S. [Obstetric analgesia from the perspective of the anaesthesiologist - Experience from the UK]. Anest Intenziv Med 2013;24(2):102-6. [In Czech].

21. Štourač P. [Obstetric Anaesthesia and Analgesia Month Attributes -report about anaesthesiology experience in Czech obstetric departments]. Anest Intenziv Med 2013;24 (2):81-2. [In Czech].

22. D'Onofrio P, Novelli AM, Mecacci F, Scarselli G. The efficacy and safety of continuous intravenous administration of remifentanil for birth pain relief: an open study of 205 parturients. Anesth Analg 2009;109(6):1922-4.

23. Buehner U, Broadbent JR, Chesterfield B. Remifentanil patientcontrolled analgesia for labour: a complete audit cycle. Anaesth Intensive Care 2011;39(4):666-70.

24. Balki M, Kasodekar S, Dhumne S, Bernstein P, Carvalho JC. Remifentanil patient-controlled analgesia for labour: optimizing drug delivery regimens. Can J Anaesth 2007;54(8):626-33.

25. Balcioglu O, Akin S, Demir S, Aribogan A. Patient-controlled intravenous analgesia with remifentanil in nulliparous subjects in labor. Expert Opin Pharmacother 2007;8(18):3089-96.

26. Volikas I, Male D. A comparison of pethidine and remifentanil patientcontrolled analgesia in labour. Int J Obstet Anesth 2001;10(2):86-90.

27. Blair JM, Dobson GT, Hill DA, McCracken GR, Fee JP. Patient controlled analgesia for labour: a comparison of remifentanil with pethidine. Anaesthesia 2005;60(1):22-7.

28. Evron S, Ezri T, Protianov M, Muzikant G, Sadan O, Herman A, Szmuk $P$. The effects of remifentanil or acetaminophen with epidural ropivacaine on body temperature during labor. J Anesth 2008;22(2):10511.

29. Volikas I, Butwick A, Wilkinson C, Pleming A, Nicholson G. Maternal and neonatal side-effects of remifentanil patient controlled analgesia in labour. Br J Anaesth 2005;95(4):504-9.

30. Blair JM, Hill DA, Fee JP. Patient-controlled analgesia for labour using remifentanil: a feasibility study. Br J Anaesth 2001;87(3):415-20.

31. Volmanen $P, A$ kural El, Raudaskoski T, Alahuhta S. Remifentanil in obstetric analgesia: a dose-finding study. Anesth Analg 2002;94(4):9137.

32. Marwah R, Hassan S, Carvalho JC, Balki M. Remifentanil versus fentanyl for intravenous patientcontrolled labour analgesia: an observational study. Can J Anaesth 2012;59(3):246-54.

33. Douma MR, Verwey RA, Kam-Endtz CE, van der Linden PD, Stienstra R. Obstetric analgesia: a comparison of patient-controlled meperidine, remifentanil, and fentanyl in labour. Br J Anaesth 2010;104(2):209-15.

34. Tveit TO, Seiler S, Halvorsen A, Rosland JH.. Labour analgesia: a randomised, controlled trial comparing intravenous remifentanil and epidural analgesia with ropivacaine and fentanyl. Eur J Anaesthesiol 2012;29(3):129-36.

35. Evron S, Glezerman M, Sadan O, Boaz M, Ezri T. Remifentanil: a nove systemic analgesic for labor pain. Anesth Analg 2005;100(1):233-8.

36. Pasha $H$, Basirat Z, Hajahmadi $M$, Bakhtiari A, Faramarzi $M$, Salmalian $\mathrm{H}$. Maternal expectations and experiences of labor analgesia with nitrous oxide. Iran Red Crescent Med J 2012;14(12):792-7.

37. Volmanen P, Akural E, Raudaskoski T, Ohtonen P, Alahuhta S. Comparison of remifentanil and nitrous oxide in labour analgesia. Acta Anaesthesiol Scand 2005;49(4):453-8.

38. Leong WL, Sng BL, Sia AT. A comparison between remifentanil and meperidine for labor analgesia: a systematic review. Anesth Analg 2011;113(4):818-25.

39. Schnabel A, Hahn N, Broscheit J, Muellenbach RM, Rieger L, Roewer N, Kranke P. Remifentanil for labour analgesia: a meta-analysis of randomised controlled trials. Eur J Anaesthesiol 2012;29(4):177-85.

40. Ng TK, Cheng BC, Chan WS, Lam KK, Chan MT. A double-blind randomised comparison of intravenous patientcontrolled remifent- 
anil with intramuscular pethidine for labour analgesia. Anaesthesia 2011;66(9):796-801.

41. Volmanen P, Sarvela J, Akural El, Raudaskoski T, Korttila K, Alahuhta S. Intravenous remifentanil vs. epidural levobupivacaine with fentanyl for pain relief in early labour: a randomised, controlled, doubleblinded study. Acta Anaesthesiol Scand 2008;52(2):249-55.

42. El-Kerdawy H, Farouk A. Labor analgesia in preeclampsia: remifentanil patient controlled intravenous analgesia versus epidural analgesia. Middle East J Anesthesiol 2010;20(4):539-45.

43. Douma MR, Middeldorp JM, Verwey RA, Dahan A, Stienstra R. A randomised comparison of intravenous remifentanil patient-controlled analgesia with epidural ropivacaine/sufentanil during labour. Int J Obstet Anesth 2011;20(2):118-23.

44. Ismail MT, Hassanin MZ. Neuraxial analgesia versus intravenous remifentanil for pain relief in early labor in nulliparous women. Arch Gynecol Obstet 2012;286(6):1375-81.

45. Huang Z, Shyu ML, Tien J, Vigoda M, Birnbach D. KnowledgeAssisted Sequential Pattern Analysis with Heuristic Parameter Tuning for Labor Contraction Prediction. IEEE J Biomed Health Inform 2014;18(2):492-9.

46. Thurlow JA, Laxton $\mathrm{CH}$, Dick A, Waterhouse $P$, Sherman L, Goodman NW. Remifentanil by patient-controlled analgesia compared with intramuscular meperidine for pain relief in labour. $\mathrm{Br} J$ Anaesth 2002;88(3):374-8.

47. Ngan Kee WD, Khaw KS, Ma KC, Wong AS, Lee BB, Ng FF. Maternal and neonatal effects of remifentanil at induction of general anesthesia for cesarean delivery: a randomized, double-blind, controlled trial. Anesthesiology 2006;104(1):14-20.

48. Babenco HD, Conard PF, Gross JB. The pharmacodynamic effect of a remifentanil bolus on ventilatory control. Anesthesiology 2000;92(2):393-8.

49. Volmanen PV, Akural El, Raudaskoski T, Ranta P, Tekay A, Ohtonen P Alahuhta S. Timing of intravenous patient-controlled remifentanil bolus during early labour. Acta Anaesthesiol Scand 2011;55(4):48694.

50. Arfeen Z, Armstrong PJ, Whitfield A. The effects of Entonox and epidural analgesia on arterial oxygen saturation of women in labour. Anaesthesia 1994;49(1):32-4.

51. Griffin RP, Reynolds F. Maternal hypoxaemia during labour and delivery: the influence of analgesia and effect on neonatal outcome. Anaesthesia 1995;50(2):151-6.

52. Waring J, Mahboobi SK, Tyagaraj K, Eddi D. Use of remifentanil for labor analgesia: the good and the bad. Anesth Analg 2007;104(6):1616-7.

53. Bonner JC, McClymont W. Respiratory arrest in an obstetric patient using remifentanil patient-controlled analgesia. Anaesthesia 2012;67(5):538-40.

54. Marr R, Hyams J, Bythell V. Cardiac arrest in an obstetric patient using remifentanil patient-controlled analgesia. Anaesthesia 2013:68(3):283-7

55. Hill D. Remifentanil in obstetrics. Curr Opin Anaesthesiol 2008:21(3):270-4

56. Hinova A, Fernando R. Systemic remifentanil for labor analgesia. Anesth Analg 2009;109(6):1925-9.

57. Volmanen P, Palomaki O, Ahonen J. Alternatives to neuraxial analgesia for labor. Curr Opin Anaesthesiol 2011;24(3):235-41

58. Kranke P, Girard T, Lavand'homme P, Melber A, Jokinen J, Muellenbach RM, Wirbelauer J, Hönig A. Must we press on until a young mother dies? Remifentanil patient controlled analgesia in labour may not be suited as a "poor man's epidural". BMC Pregnancy Childbirth 2013;13:139.

59. Stourac P, Brachaczkova Z, Holeckova P, Nedomova L. Obstetric Analgesia. Educational portal AKUTNE.CZ [serial on the internet, ISSN 1803-179X]. 2015 Jun [cited 2015 Jul 16]. Available from: http://www.akutne.cz/index-en.php?pg=education--interactivealgorithms\&tid=209 